\title{
Erratum to: Quantitative assessment of possible human health risk associated with consumption of arsenic contaminated groundwater and wheat grains from Ropar Wetland and its environs
}

\author{
Sakshi Sharma • Jagdeep Kaur • \\ Avinash Kaur Nagpal • Inderpreet Kaur \\ Published online: 3 December 2016 \\ (C) Springer International Publishing Switzerland 2016
}

Erratum to: Environ Monit Assess (September 2016) 188, Issue 9:506

DOI 10.1007/s10661-016-5507-9

The original version of this article unfortunately contained a mistake in the article title.

The article title should have been Quantitative assessment of possible human health risk associated with consumption of arsenic contaminated groundwater and wheat grains from Ropar Wetland and its environs not Quantitative assessment of possible human health risk associated with consumption of arsenic contaminated groundwater and wheat grains from Ropar Wetand and its environs. The corrected article title is shown above.

The online version of the original article can be found at http://dx. doi.org/10.1007/s10661-016-5507-9.

S. Sharma · J. Kaur · A. K. Nagpal

Department of Botanical and Environmental Sciences, Guru

Nanak Dev University, Amritsar, Punjab 143005, India

I. Kaur $(\square)$

Department of Chemistry, Centre of Advance Studies, Guru

Nanak Dev University, Amritsar, Punjab 143005, India

e-mail: inderpreet11@yahoo.co.in 